Résumés des conférences et travaux

$145 \mid 2014$

2012-2013

\title{
Mondes élamites et achéménides
}

\section{Mondes élamites et achéménides}

Conférences de l'année 2012-2013

Wouter F. M. Henkelman

\section{OpenEdition \\ Journals}

\section{Electronic version}

URL: https://journals.openedition.org/ashp/1564

DOI: 10.4000/ashp.1564

ISSN: 1969-6310

\section{Publisher}

Publications de l'École Pratique des Hautes Études

\section{Printed version}

Date of publication: 1 September 2014

Number of pages: 19-21

ISSN: 0766-0677

Electronic reference

Wouter F. M. Henkelman, "Mondes élamites et achéménides", Annuaire de l'École pratique des hautes études (EPHE), Section des sciences historiques et philologiques [Online], 145 | 2014, Online since 28 November 2014, connection on 06 July 2021. URL: http://journals.openedition.org/ashp/1564 ; DOI: https://doi.org/10.4000/ashp.1564 


\title{
MONDES ÉLAMITES ET ACHÉMÉNIDES
}

\author{
Maître de conférences : M. Wouter F. M. Henkelman
}

Programme de l'année 2012-2013 : Teispès et les Perses.

Les cours proposés en 2012-2013 avaient le même fil rouge : une introduction à la langue (inscriptions royales élamites : langue et idéologie) et une enquête historique (L'empire perse vu de Persépolis : les tablettes dites des Fortifications dans le contexte de l'histoire et culture achéménide) traitant largement des processus d'acculturation et d'intégration entre les Élamites et les Iraniens durant le premier millénaire avant notre ère. Cette importante transformation a touché autant les habitants originels de l'Iran du Sud-Ouest et leur culture que les nouveaux groupes émergents d'iranophones. Il en a résulté la création d'une nouvelle identité : celle des Perses.

Vu dans ce contexte, l'Empire perse ou achéménide n'était pas une création ex nihilo de Cyrus le Grand en 550 av. J.-C. environ, mais la conséquence d'un long processus. Le passé pré-perse était aussi important que les conquêtes militaires qui s'ensuivirent. L'État néo-élamite (en Iran du Sud-Ouest), par exemple, semble avoir témoigné d'un développement remarquable de la culture matérielle. La richesse des inventaires des tombes d'Arğān et, plus récemment de Rām Hormoz, témoigne de cela. Une partie du contexte est probablement à trouver dans l'ouverture de nouvelles routes de commerce au sud, qui connecta l'Est de l'Afrique et la péninsule arabe, via le Sud de la Babylonie et l'Élam, au Nord-Ouest de l'Inde. Parmi d'autres indications, on trouve des références à la myrrhe et à l'encens (de l'Est de l'Afrique et du Sud de l'Arabie) dans ce qu'on appelle l'archive de l'Acropole, un petit corpus de textes administratifs du palais de Suse à l'époque néo-élamite tardive (environ 600 av. J.-C.). On peut imaginer comment les premiers Perses ont profité de ces réseaux quand ils sont entrés dans le théâtre global : leur monde était déjà un monde connecté.

Les résultats de l'acculturation élamo-iranienne sont clairement visibles dans nos sources, que ce soit en termes de religion, d'iconographie, de language, d'administration ou de culture matérielle. Ainsi, dans le cœur de l'empire, à Pārsa (la province moderne du Fārs), nous avons un ample corpus de tablettes d'argiles, l'archive des Fortifications de Persépolis (509-493 av. J.-C.), qui témoigne d'un panthéon mixte. Les dieux d'origines élamite et iranienne (i.e. indo-iranienne) sont vénérés côte à côte. La terminologie des sacrifices est un mélange de termes élamites et vieil-iraniens, et la même chose se remarque pour les titres des prêtres. Par le passé, des tentatives ont été faites pour séparer tous ces éléments en deux différentes sphères cultuelles, mais une analyse détaillée des tablettes pertinentes montre que cela est impossible. Les vieux dieux élamites n'étaient pas vénérés pour le compte d'une population élamite résiduelle, et ils ne doivent pas non plus être vus comme des divinités qui étaient « tolérées » par le gouvernement perse : ils étaient vénérés parce qu'ils appartenaient au paysage religieux local. 
Un exemple parlant, récemment édité, est celui des Fort. 1316-101, appelé « journal » (registre), qui parle d'allocations d'orge pour diverses raisons à un endroit le long de la route de Persépolis, à Médie. Ce n'est pas une zone où la culture élamite est connue pour avoir été très présente à la période pré-achéménide. Et déjà, parmi les allocations, sont mentionnées des quantités pour Napiriša (11. 14' et rev. 28'-29'), un dieu d'origine élamite dont le culte doit avoir été introduit dans la région nord par les Achéménides.

Les dieux dans le panthéon du cœur achéménide étaient devenus, en d'autres termes, aussi perses que les Perses eux-mêmes: ils faisaient partie d'une identité incluse qui avait absorbé des éléments des traditions élamite, indo-iranienne ou d'autres encore (mésopotamienne). Cette capacité à former une nouvelle synthèse, qui peut facilement être définie comme une caractéristique centrale de la culture iranienne à travers les âges, est aussi reflétée dans l'art perse. Les structures et reliefs fameux de Takht-e Ğamš̄id (Persépolis) combinent avec grâce les traditions artistiques et techniques de plusieurs parties de l'empire.

L'archive des Fortifications de Persépolis susmentionnée est un corpus de tablettes qui sont rédigées, pour la majeure partie, en élamite, et, pour une moindre part en araméen. Tant par sa langue dominante que par les structures administratives et bureaucratiques qu'elle documente, l'archive montre combien les Perses sont redevables à leurs prédécesseurs élamites. L'économie institutionnelle domestique à grande échelle, centrée à Persépolis, continue des structures néo-élamites plus anciens d'une économie de redistribution centralisée. Mais peut-être plus impressionnant est la langue ellemême, une forme tardive et particulière d'élamite. Comme cela a été continuellement observé durant le cours de langue, ce type d'élamite représente en réalité une variété de langue réduite morpho-syntaxiquement et restructurée. L'élamite utilisé à Persépolis n'était pas une continuation linéaire du langage employé dans les inscriptions royales du second et du début du premier millénaire de Suse et ailleurs en Élam. Au contraire, il trahit une vaste influence des locuteurs qui l'utilisaient comme deuxième langue : les Perses pour lesquels le vieil-iranien occidental était la première langue. Ils ont acquis une forme d'élamite dans un but administratif et peut-être, à une date plus ancienne, pour leur contact avec l'État néo-élamite très développé et sa culture urbaine. Leur version de la langue n'était donc pas « parfaite », mais une version simplifiée et restructurée, en particulier ces éléments qui étaient étrangers aux locuteurs d'une langue indo-européenne. Le résultat était un élamite qui ressemblait davantage à du vieil-iranien, et présentait l'avantage d'une l'alternance du code linguistique entre les deux langues qui devenait plus aisé.

Le fait que les (premiers) Perses auraient voulu apprendre l'élamite peut surprendre, mais en fait la culture élamite en général était séduisante pour eux. Dans une partie du monde où la culture Perse a vu le jour, Elam était la force dominante, avec une structure d'État développée, des réseaux économiques et des traditions artistiques remontant à des millénaires. L'attraction pour cette culture peut être entrevue dans les noms et titres de quelques-uns des premiers souverains. Le fondateur Cyrus se présentait lui-même, dans le fameux Cylindre de Cyrus, comme Kuraš d'Anšan, petit-fils de Kuraš d'Anšan, fils de Šišpiš. Le titre, " (souverain) d'Anšan » relie Cyrus aux rois élamites « de Suse et d'Anšan ». En ce qui concerne le nom du fondateur du premier 
empire « aryen », malgré de nombreuses tentatives pour trouver une étymologie indoiranienne, la solution la plus probable reste celle d'un nom élamite. Cela a été suggéré il y a 110 ans par Friedrich Carl Andreas, à partir d'une supposition logique, à savoir que le vieil iranien Kuruš doit être une adaptation de la forme élamite Kuraš. Le nom est probablement abrégé, un phénomène bien établi pour les noms royaux néo-élamites. Une interprétation possible est « [dieu x] a protégé » ${ }^{1}$, auquel on peut comparer le nom féminin Šeraš, « [dieu x] a commandé ».

Une explication parallèle, qui est apparue durant l'une des sessions sur l'histoire achéménide, peut maintenant être proposée pour Teispès, l'ancêtre de Cyrus. Son nom (Teispès est la forme grecque) est connu sous plusieurs formes : Čišpiš en vieux-perse, Šišpiš en akkadien, Š ešpeš et Zišspiš en élamite. Parmi ces formes variées, l'élamite Šěspeš est la plus ancienne, attestée dans une inscription disant « Kuraš d'Anšan, fils de Šešpeš ». Cette inscription est inscrite sur un sceau (PFS 0093*) qui peut avoir appartenu à un ancêtre du fondateur Cyrus et qui peut être daté de la fin du septième siècle avant notre ère ${ }^{2}$.

Parce qu'aucune étymologie convaincante pour la forme iranienne, Čišpiš, n'existe, il a déjà été suggéré de chercher une étymologie élamite ${ }^{3}$. Cela peut maintenant être proposé sur la base de la forme Šešpeš, qui peut dériver de la racine šepi-, šip $(i)$-, « vouer » (cf. vieil-élamite Šep-Sinn, élamite achéménide Šep-šilla, et la fête sacrificielle šip). Šešpeš pourrait être une forme verbale, basée sur une base verbale redoublée. Le développement proposé serait par conséquent le suivant : *šepšepeš > * šepšpeš > šešpešs, ce qui est en accord avec l'élision régulière de la voyelle dans la seconde syllabe, causée par l'accent tonique portant sur la première. Si cela est correct, le nom peut approximativement être interprété comme « il a voué [au dieu x] ». $\mathrm{Au}$ temps du fondateur Cyrus, le nom de l'ancêtre Šešpes avait déjà été iranisé en Čišpiš, qui a été ensuite à nouveau transposé en élamite (dans l'inscription de Bīsotūn) en Zišpiš.

Au lieu d'une énigme étymologique tenace, « Teispès » nous apparaît finalement comme une petite vignette des relations culturelles complexes sous-jacentes à l'identité perse. Commençant comme le nom élamite d'un ancien souverain perse dans un monde où Élam était encore une forme dominante, il est bientôt devenu si enraciné dans l'imagination perse d'un ancêtre sanctifié, qu'il n'a plus été reconnu comme élamite.

1. Henkelman, «Persians, Medes and Elamites. Acculturation in the Neo-Elamite period», dans G. Lanfranchi, et al. (éd.), Continuity of Empire (?): Assyria, Media, Persia, Padoue, 2003 (History of the Ancient Near East / Monographs series 5), p. 181-231

2. Sur le sceau voir M. B. Garrison, «The Seal of "Kuraš the Anzanite, Son of Šešpeš" (Teispes), PFS 93*: Susa - Ansan - Persepolis », dans M. Garrison et J. Álvarez-Mon (éd.), Elam and Persia, Winona Lake, 2011, p. 375-405.

3. Ainsi J. Tavernier, Iranica in the Achaemenid Period (ca. 550-330 B.C.). Lexicon of Old Iranian Proper Names and Loandwords, Attested in Non-Iranian Texts (OLA 158), Louvain, p. 519 (ibid. $528 f$. sur Cyrus). 